\title{
CONTRIBUIÇÕES DO ESTUDO DESCRITIVO PARA O ENSINO DE LÍNGUA PORTUGUESA: O VERBO PERDER
}

\section{CONTRIBUTIONS OF DESCRIPTIVE STUDY OF VERBS FOR TEACHING PORTUGUESE: THE VERB PERDER}

\author{
Liliane Alves Santana MALACOSKI \\ (SEEES) \\ lilianemalacoski@gmail.com \\ Keila Mara SCHNEIDER \\ (SEEES) \\ keila.schneider@outlook.com \\ Aucione das Dores SMARSARO \\ (UFES) \\ aucione@uol.com.br
}

Resumo: Este artigo tem como objetivo apresentar uma discussão a respeito da importância de estudos descritivos de verbos para o ensino de Língua Portuguesa. Conforme o contexto de uso em que o verbo perder está inserido ele pode funcionar como o núcleo da predicação, ou como componente de uma sequência fixa, ou como verbo-suporte. As análises das estruturas com o verbo perder são feitas com base no modelo teórico-metodológico do LéxicoGramática, postulado pelo linguista francês Maurice Gross (1975), que define critérios sintáticos formais para a descrição lexical em contextos linguísticos. $O$ principal objetivo dessa análise é mostrar a importância da descrição lexical para o ensino de Língua Portuguesa. A partir das análises e da descrição verbal, concluímos que o verbo perder é muito produtivo como verbo suporte, e também como componente de expressão fixa. Essas noções não são colocadas nos manuais didáticos ou gramáticas tradicionais. A descrição lexical pode contribuir para um melhor ensino de língua portuguesa, uma vez que o professor, com posse desse estudo descritivo, poderá explorar melhor as noções lexicais, tendo em vista a correlação entre morfologia, sintaxe e semântica, além de despertar 0 interesse do aluno para as várias manifestações de produção de sentido do léxico, propondo reflexões sobre o funcionamento da língua.

Palavras-chave: Léxico. Verbo Perder. Ensino. Descrição.

\begin{abstract}
This article aims to present a discussion about the importance of descriptive studies of verbs for Portuguese teaching. In accordance with the context of use that the verb perder it is inserted, it can work like nucleus of predications, or like component of a fixed sequence, or like a support verb. The structures with the verb perder analysis are made based in the theoretical and methodological model of Lexicon-Grammar, postulated by French linguist Maurice Gross (1975), it defines formal syntactic criteria for lexical description in linguistic contexts. The main objective of this analysis is to show the importance of lexical description for the Portuguese teaching. From the analysis and the
\end{abstract}


verbal description, we conclude that the verb perder is very productive as a support verb, as well as fixed-term component. These notions are not placed in textbooks or traditional grammars. Lexical description can contribute to a better Portuguese teaching, since the teacher, with possession of this descriptive study, can better exploit the lexical notions, given the correlation between morphology, syntax and semantics, in addition to arouse the interest of the student to the various manifestations of the lexical meaning production, proposing reflections on the functioning of the language.

Keywords: Lexicon, Verb Perder, Teaching, Description.

\section{Apresentação}

Este artigo tem o objetivo de discutir a importância de estudos descritivos para o ensino de língua portuguesa. Para isso, escolhemos o verbo perder como objeto de análise, identificando suas propriedades de acordo com o contexto em que é utilizado.

A morfologia e a sintaxe ainda são apresentadas de forma tradicional aos alunos, o estudo de nomenclaturas ainda é predominante em relação ao estudo da produção de sentido provocada pelos itens lexicais em textos.

No entanto, sabemos que as palavras, em seus contextos variados, podem apresentar diferentes sentidos. Por isso, é necessário que os alunos compreendam essa produção de sentidos, para que possam compreender e interpretar os textos.

O verbo perder, assim como outros verbos da língua portuguesa, comporta-se de maneira diferente, de acordo com o contexto. Para identificar os sentidos e as propriedades desse verbo, utilizamos como base teórica metodológica o Léxico-Gramática, do linguista francês Maurice Gross.

Aplicamos testes formais previstos pelo Léxico-Gramática, a fim de discutirmos as propriedades sintático-semânticas do verbo perder. Com esses testes, pode-se perceber que morfologia, sintaxe e semântica caminham juntas na construção de sentidos de um texto. Por isso, na sala de aula, torna-se interessante observar a língua de uma forma global, não em partes isoladas.

\section{O ensino de Morfologia}


Os estudos morfológicos apresentados na educação básica ainda têm caráter tradicional. As palavras e classes de palavras são mostradas de forma dissociada dos textos, como se aquelas não os constituíssem.

Segundo o PCNEM,

A perspectiva dos estudos gramaticais na escola, até hoje centra-se, em grande parte, no entendimento da nomenclatura gramatical como eixo principal; descrição e norma se confundem na análise da frase, essa deslocada do uso, da função e do texto. (PCNEM, p. 16)

O que ainda encontramos, tanto nos livros didáticos quanto nas aulas, é um ensino descontextualizado, em que é mostrado ao aluno palavras e frases soltas, gerando outro problema, eles sentem dificuldade para interpretar e compreender textos simples.

\section{A importância da descrição para o ensino}

O trabalho de descrição a partir do Léxico-Gramática (GROSS, 1975) contribui com o ensino, uma vez que a partir dessas descrições podemos observar e descrever o comportamento sintático-semântico dos itens lexicais do português. Esse conhecimento, quando nas mãos do professor, permite que as palavras possam ser consideradas como elementos construtores de sentido, e que esse pode variar de acordo com contexto. Dessa maneira, um professor que tenha conhecimento acerca da descrição lexical, poderá fazer um trabalho para além do livro didático, de modo a despertar no aluno a motivação, o interesse e a capacidade de verificar como o verbo se comporta em cada situação, como são entendidas as relações de sentido.

Com essa abordagem, pode-se discutir o verbo a partir da visão da construção de sentidos, indo além do trabalho de decorar conjugações, tempos e modos, como ainda é mostrado em alguns livros didáticos. O estudo descritivo possibilita que o aluno conheça e reconheça os comportamentos do verbo, que se diferem nos diversos contextos de uso. Ora o verbo se apresenta indispensável em uma estrutura, José perdeu as chaves; ora se apresenta como elemento de uma sequência fixa, José perdeu a cabeça com o colega; ora se apresenta como verbo-suporte, José perdeu a paciência com Ana. Este 
estudo permite que tanto o educando quanto os educadores compreendam que o sentido do léxico é indissociável da gramática. Dito de outro modo, o sentido do verbo perder e dos demais verbos da língua depende da estrutura sintática em que ele se encontra.

Esperamos que a descrição do verbo perder, assim como de outros verbos, tragam mudanças na prática de sala de aula, para que o ensino mostre a produtividade e a variação da nossa língua, e para que ele esteja vinculado à real funcionalidade desta língua e, também, à realidade do aluno; esperamos, também, que os autores de livros didáticos busquem mais sobre as recentes trabalhos descritivos da língua, para que o verbo seja trabalhado de forma mais reflexiva, tendo como objetivo formar alunos que possam ler e escrever, e não decorar as classificação das palavras da língua.

\title{
2.1 Léxico-Gramática
}

Como pressuposto teórico para a descrição do verbo perder elencamos o quadro teórico-metodológico do Léxico-Gramática definido pelo linguista francês Maurice Gross (1975).

O Léxico-Gramática foi proposto por Maurice Gross durante os anos 1960, mas foi somente nos anos 80 que se consolidou (BARROS, 2014).

\begin{abstract}
A primeira proposta de uma teoria do léxico-Gramática feita por Maurice Gross, no Laboratoire d'automatique documentaire et linguistique (LADL), na França, data de 1968, quando já se propunha um programa de pesquisa de levantamento de construções léxico-gramaticais. Nos anos 70, essa proposta se consolida e em meados dos anos 80 é adotado o nome de Léxico-Gramática. (BARROS, 2014, p. 26)
\end{abstract}

O Léxico-Gramática surgiu com os estudos de um grupo de linguistas do LADL (Laboratoire d'automatiquedocumentaireetlinguistique, Université Paris). Esse grupo "descreveu importantes segmentos da gramática do francês, com um objetivo de exaustão do ponto de vista lexical" (LAPORTE, 2000, p. 4).

Gross usou o modelo Transformacional e o Distribucionismo de Zelling Harris como base para o seu modelo de análise linguística (RASSI; VALE, 2013).

O linguista propôs combinar o léxico e a gramática, pois 
(...) os elementos lexicais podem se combinar gramaticalmente de formas bastante específicas nas línguas, ou seja, nem todo item lexical pode ocupar qualquer posição sintática, devendo adequar-se a determinadas restrições semânticas que a sintaxe lhe impõe, e as restrições sintáticas impostas pela semântica. (RASSI; VALE, 2013, p. 108)

O nome Léxico-Gramática surge a partir do momento em que se acredita que os itens lexicais apresentam características próprias, e, por isso, todas as palavras do léxico devem ser descritas.

A teoria do L-G defende que cada item lexical de uma língua possui uma gramática própria e essa gramática deve ser descrita formalmente; daí decorre o nome Léxico-Gramática, admitindo-se que há uma gramática específica para cada unidade lexical de uma língua (RASSI; VALE, 2013, p. 108).

Segundo Picoli (2015), a descrição sintático-semântica das estruturas para ser utilizada no PLN, de acordo com as orientações do método do LéxicoGramática, necessita de uma formalização.

Para o Léxico-Gramática, esse tipo de descrição deve ser feita por meio da análise e descrição dos itens lexicais inseridos em frases, pois as palavras só passam a ter sentido dentro de frases.

Inserindo um item lexical numa frase, podem-se manipular sequências de termos, fazendo transformações, para descrever determinada palavra. Assim, é frequentemente observada, na frase, uma inter-relação entre léxico e sintaxe (PICOLI, 2015, p. $39-40$ ).

\section{A descrição do verbo perder}

Para realizar a descrição do verbo perder, seguimos uma das práticas metodológicas do Léxico-Gramática, que consiste em analisar a palavra em contextos frasais, ou seja, não se deve analisar a palavra/ verbo isoladamente, uma vez que seu sentido depende das relações sintáticas. Em alguns casos, ocorre a ambiguidade, como em Ana perdeu a prova, que pode ter uma dupla interpretação: uma, Ana deixou de fazer a prova, e outra, Ana deixou de ter a posse da prova (objeto concreto); assim como em Paulo perdeu o filho; Joséperdeu a cabeça; Ana perdeu a aliança. A eliminação da ambiguidade acontece somente com a presença de mais complementos, dessa forma pode- 
se descrever e diferenciar todas as possibilidades de significação do verbo perder.

Na estrutura Ana perdeu a prova, o verbo está funcionando como verbo pleno com o sentido de não chegar a tempo. Acrescentando um locativo como em Ana perdeu a prova na biblioteca, o verbo está funcionando como verbo pleno com o sentido prototípico de terminação de posse. O mesmo acontece na estrutura Paulo perdeu o filho, o verbo apresenta duas significações com duas estruturas funcionando como pleno: uma, com o sentido de morte de uma pessoa relacionada, e outra, com o sentido prototípico acrescida de um locativo como em Paulo perdeu o filho no aeroporto.

Outra estrutura descrita com duas entradas foiperder a cabeça: em uma delas o verbo está funcionando como verbo pleno, com sentido de amputação, como em João Batista perdeu a cabeçana guilhotina, e a outra, como componente de expressão fixa José perdeu a cabeça com o amigo.

$\mathrm{Na}$ estrutura perder a aliança, a ambiguidade é lexical. O verbo foi descrito como verbo suporte em O Brasil perdeu a aliança com a Bolívia, e como verbo pleno com sentido prototípico em Ana perdeu a aliança na rua.

\section{A Gramática Tradicional e Novas Tendências}

Todos os itens lexicais da Língua Portuguesa são produtores de sentidos. Assim, cada escolha lexical tem um propósito. Por isso, os vários sentidos que um verbo, por exemplo, pode adquirir, nos diferentes contextos de uso, devem ser explorados em sala de aula, assim como a aquisição de novos sentidos.

A língua não deve ser ensinada como estática, pois as palavras podem adquirir novos sentidos, como pode ser percebido na análise das estruturas com o verbo perder, e novas palavras podem ser criadas, como afirma Antunes (2012):

A constante expansão do léxico da língua se efetua pela criação de novas palavras (doleiro, internetês), pela incorporação de palavras de outras línguas (deletar, mouse, leiaute, tuitar, blogar), pela atribuição de novos sentidos a palavras já existentes (salvar, fonte, vírus), processos que costumam coexistir e deixar o léxico em um ininterrupto movimento de renovação. (ANTUNES, 2012, p. 31) 
Acreditar na unidade de uma língua é desconsiderar a variação linguística, e, desta forma, desconsiderar, também, o conhecimento de mundo do aluno.

Desta forma, é importante mostrar, na sala de aula, a variedade do léxico e como as palavras podem ocorrer em diferentes contextos de uso, uma vez que a língua não é estática.

De acordo com Freire (1999, apud FARIAS, 2009) o ensino transmissivo, isto é, prescritivo, domestica a curiosidade. Existem outras formas de abordar os estudos de língua de maneira a despertar no aluno a curiosidade e motivação.

(...) devo saber que sem curiosidade que move, que me inquieta, que me insere na busca, não aprendo nem ensino. [...] Com a curiosidade domesticada posso alcançar a memorização mecânica do perfil deste ou daquele objeto, mas não o aprendizado real ou o conhecimento cabal do objeto. (FREIRE, 1999, p. 95 apud FARIAS, 2009)

Sendo assim, torna-se importante para o ensino de Língua Portuguesa apresentar as várias significações de uma mesma palavra que estão presentes no cotidiano linguístico. O ensino sobre verbos ainda é o tradicional método de apresentar apenas as conjugações, os tempos e os modos. Contudo, este procedimento não contempla a língua em funcionamento. Em contra partida, o Léxico-Gramática analisa e classifica os verbos, tendo em vista a correlação entre sintaxe e semântica. Sendo assim, o estudo descritivo se faz importante uma vez que analisa o léxico em uso. Conforme Antunes,

(...) o estudo do léxico deve superar a simples identificação de seus significados dicionarizados para abranger as especificações, os deslizamentos, as expansões ou restrições de sentido que as palavras sofrem. Tal objetivo somente é possível pela análise persistente de textos reais, orais e escritos que acontecem nas mais diferentes agências e nos mais diversos suportes da comunicação diária. (ANTUNES, 2010, p. 185)

Os professores diante do conhecimento do funcionamento da língua, por meio de estudos descritivos, devem direcionar um ensino que reflita sobre o verbo nas situações de uso. Por exemplo, o sentido do verbo perder depende do contexto sintático em que está inserido, o sentido do verbo perder em (1) 0 Flamengo perdeu o jogo, é diferente de (2) O estudante perdeu o ônibus, (3) 
Bruno perdeu as chaves, (4) Ana perdeu a paciência (5) Carlos perdeu o emprego.

\section{A proposta: morfologia e sintaxe no texto}

Há muitas maneiras mais produtivas de se trabalhar o conteúdo verbal, de trabalhar a linguagem. A autora Morais Leite (2011) diz que linguagem é "criação de sentido, encarnação de significação e, como tal, ela dá origem à comunicação" (p.23).

O verbo perder apresenta diferentes propriedades, dependendo do contexto de uso. Por exemplo, na frase Paulo perdeu a cabeça com o amigo, o verbo apresenta uma ligação de fixidez com o objeto direto, caracterizando-o como componente de uma expressão fixa. Assim, não podemos substituir perder e cabeça por outros itens lexicais, pois a expressão perde seu significado, por exemplo, perder a mente.

Já no exemplo, No acidente de trânsito, o motociclista perdeu a cabeça, o sentido da estrutura perder a cabeça é prototípico de perder uma parte do corpo literalmente. Aqui o verbo é classificado como verbo pleno.

Vejamos a seguir alguns exemplos do cotidiano com a presença do verbo perder:

\section{SINAF 25 anos. Incrivel chegar onde chegamos perdendo um cliente atrás do outro.}

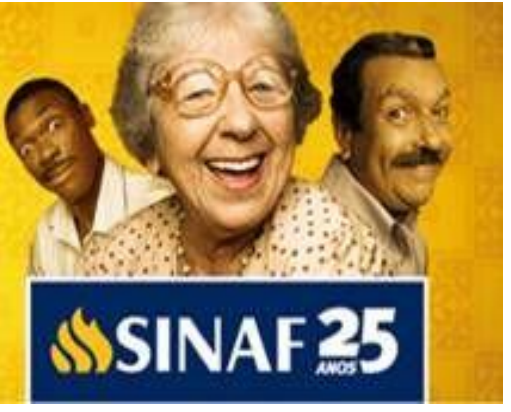

Figura 1 - Anúncio publicitário da Sinaf. (http://www.fotolog.com/milalegre/43481940/)

Pode-se observar no anúncio do seguro nacional de assistência à família (seguro de vida, assistência funeral) que o verbo perder foi intencionalmente colocado na frase para produzir uma duplicidade de sentido, gerando assim um efeito humorístico. Deste exemplo, pode-se tirar uma boa reflexão, a importância de se conhecer o funcionamento da língua. Esse conhecimento pode ser trabalhado com o aluno, para mostrar que uma escolha lexical pode 
ser determinante para se alcançar o efeito pretendido. A estrutura perder cliente apresenta duas possibilidades de interpretação. A primeira significa que a pessoa deixa de ser cliente da empresa, da loja, do supermercado etc. Nesta interpretação, o verbo não será o núcleo da significação, e sim o substantivo cliente (noção de verbo-suporte). A segunda, por se tratar aqui de uma empresa relacionada a funeral, significa morte do cliente. O verbo perder detém o núcleo semântico (noção de verbo pleno). Mas neste contexto da propaganda, prevalece a segunda interpretação, pois menciona o longo tempo que a empresa está no mercado (25 anos), seria contraditório se estivesse efetivamente deixando de ter clientes. Esse foi um recurso da língua utilizado para um fim comercial, que alcançou o objetivo mínimo de chamar a atenção para o serviço oferecido, mediante o humor provocado pela duplicidade de sentido.

\section{MUTACALANANESSA HORQ: PERDER A CABEÇA...}
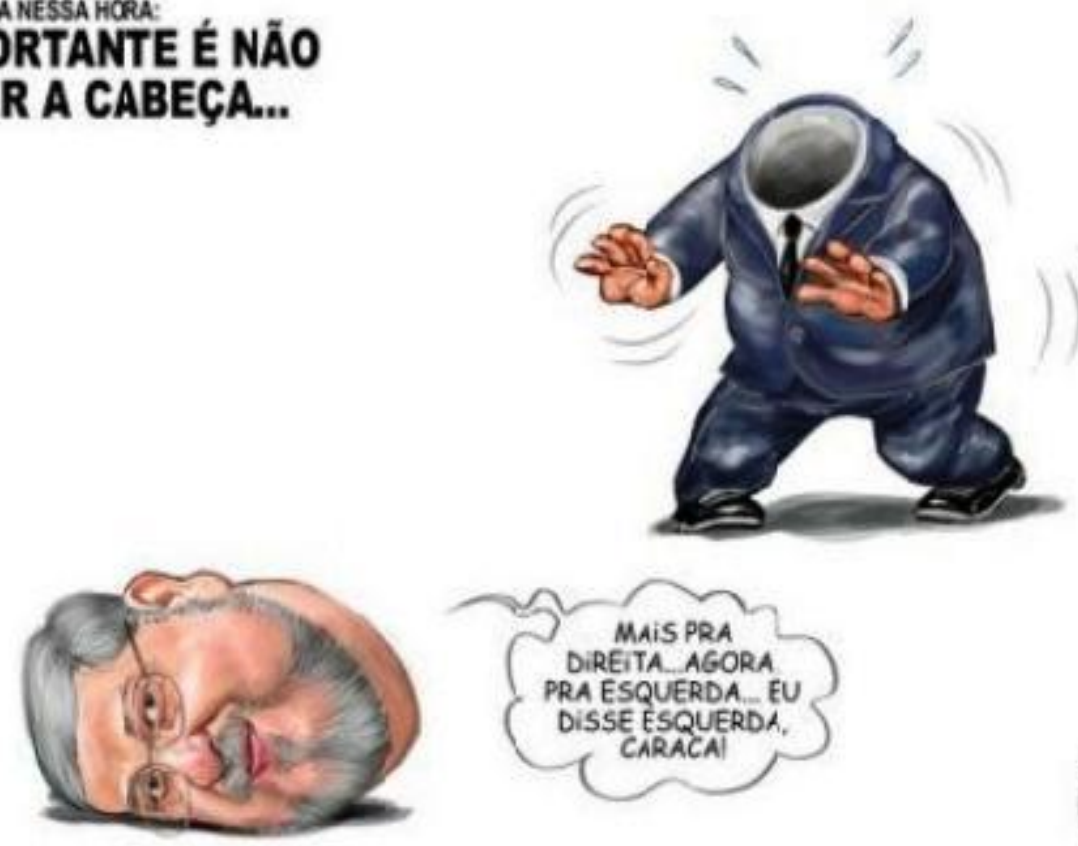

Figura 2 - Charge do dia: sem perder a cabeça.

(http://www.bocamaldita.com/1119728757/charge-do-dia-sem-perder-a-cabeca/)

Essa charge brinca com as palavras para criticar o atual momento político do Brasil. Nesse caso, perder a cabeça ganha o sentido de perder o cargo, a função que exerce, dialogando com a expressão cabeças vão rolar.

\footnotetext{
${ }^{1}$ Disponível em: <http://www.bocamaldita.com/1119728757/charge-do-dia-sem-perder-acabeca/ $\geq$. Acesso em 20 maio 2016.
} 
As imagens e a fala no balão contribuem para formar esse sentido, pois a cabeça do personagem (que é um político) está no chão, enquanto o corpo a procura. O autor ainda brinca com as palavras direita e esquerda, que se remetem aos dois grandes grupos no cenário político brasileiro. O verbo perder funciona, aqui, como um elemento de expressão cristalizada, pois os elementos não podem ser substituídos por outros.

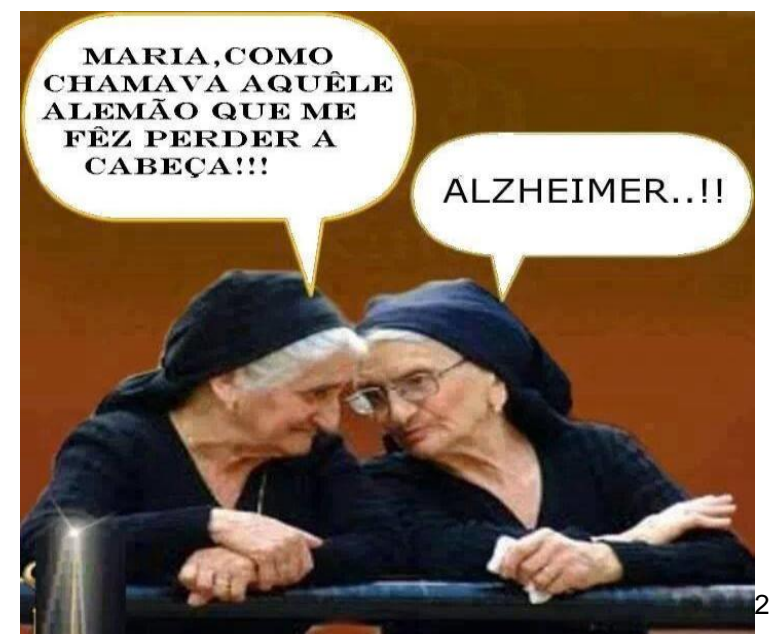

Figura 3 - Anedota: $O$ alemão que me fez perder a cabeça. (http://www.engracado.com/alemaoque-fez-perder-cabeca/)

Já neste exemplo, perder a cabeça ganha uma nova significação. Há, novamente, uma brincadeira com os sentidos que podem ser produzidos, e perder a cabeça pode ser interpretado de duas maneiras. Ao ler o primeiro balão, entende-se que a personagem faz referência a um homem alemão que a fez perder a razão, perder os sentidos de tanto amor, que a faz se apaixonar. Porém, ao ler o segundo balão com a resposta da segunda personagem, outro sentido aparece, perder a cabeça ganha o sentido de perder a memória, não se lembrar de coisas ou momentos da vida. Esse sentido só pode ser construído a partir da resposta Alzheimer, pois se espera que apareça um nome de um homem alemão, não um que se remeta à doença Alzheimer. O verbo perder, também neste caso, é um elemento de expressão cristalizada, mesmo apresentando dois sentidos diferentes.

Com estes exemplos, pode-se perceber que o verbo perder ganha sentidos diferentes de acordo com o contexto em que aparece. É importante 
ressaltar que todos os elementos do texto contribuem para a construção do sentido.

\section{Conclusão}

Sabemos que um ensino sob a perspectiva tradicionalista não suscita resultados satisfatórios em relação à aprendizagem. E pode-se constatar que a abordagem metodológica está longe de promover um ensino condizente com a realidade, visto que o léxico é apresentado, predominantemente, de forma isolada, ou seja, descontextualizada, como é percebido no conteúdo sobre verbo. É importante mostrar os sentidos que a palavra adquire dentro de contextos. Nas palavras de Antunes (2010),

O estudo do léxico é muito significativo para quem deseja ampliar suas competências comunicativas; esse estudo deve ser amplo, a fim de atingir outros mecanismos de significação para além daqueles puramente lexicais; somente a instância dos textos reais propicia o conhecimento de todas as possibilidades de sentido que o léxico de uma língua pode abranger. (ANTUNES, 2010, p.186)

Deve-se promover, minimamente, uma reflexão sobre a língua, pois a mesma palavra, o mesmo verbo ganha significações distintas conforme o propósito comunicativo. Antunes (2010) diz que "o estudo do léxico deve constituir uma das prioridades do ensino, considerando seu papel na construção do sentido global do texto, na expressão de seus propósitos comunicativos, no recíproco entendimento pretendidos pelos interlocutores". ( $p$. 212). Ainda nas palavras da autora, "convém destacar não o significado particular de cada palavra, mas as relações de significado que elas mantêm umas com as outras, o que supõe o cuidado de não considerá-las isoladamente.". (p.216)

Sendo assim, este estudo pode contribuir grandemente para a educação básica. Permite que os alunos e, principalmente, os professores conheçam os comportamentos dos verbos da língua portuguesa, que se diferem conforme 0 contexto de uso. Com isso, o professor poderá propor um ensino que contemple a língua em funcionamento, suscitando nos alunos uma reflexão e uma compreensão de que o sentido do léxico é indissociável da gramática, ou 
seja, no caso do verbo perder, seu sentido irá depender de qual estrutura sintática ele se encontra. É nesse sentido que destacamos a importância dessa descrição, para atender a necessidade de uma descrição real do funcionamento da Língua Portuguesa, que se caracteriza como uma língua dinâmica e heterogênea.

\section{Referências bibliográficas}

ANTUNES, Irandé. Análise de textos: fundamentos e práticas. São Paulo: Parábola Editorial, 2010.

ANTUNES, Irandé. Território das palavras: estudo do léxico em sala de aula. São Paulo: Parábola Editorial, 2012.

BARROS, Cláudia Dias de. Descrição e classificação de predicados nominais com o verbo-suporte fazer: especificidades do Português do Brasil. 2014. 197 f. Tese (Doutorado em Linguística). Centro de Educação e Ciências Humanas, Universidade Federal de São Carlos, São Carlos, 2014.

BRASIL. Parâmetros Curriculares Nacionais - Ensino Médio (PCNEM). Disponível em: http://portal.mec.gov.br/seb/arquivos/pdf/14_24.pdf. Acesso em 25 de maio de 2016.

FARIAS, I.M.S. de et al. "A aula como espaço-tempo coletivo de construção de saberes". Didática e docência: aprendendo a profissão. Brasília, DF: Líber livro, 2009. p.153-63.

GROSS, Maurice. Méthodes en syntaxe. Paris: Hermann, 1975.

LAPORTE, Éric. A Linguística para o processamento das línguas. Recortes Linguísticos. Saberes: Vitória, 2000. p. 67-75. Disponível em: $<$ http://halshs.archives-ouvertes.fr/docs/00/36/94/10/PDF/vitoria.pdf>. Acesso em 25 de maio de 2016.

MORAES LEITE, Lígia Chiappini. "Gramática e Literatura: Desencontros e esperanças". In: GERALDI, João Wanderley (org.). $\mathbf{O}$ texto na sala de aula. 5 ed. São Paulo, Editora Ática, 2011.

PICOLI, Larissa. Descrição de verbos de base adjetiva derivados com os sufixos -ecer e -izar, para o Processamento Automático de Linguagem Natural. 2015. 112 f. Dissertação (Mestrado em Estudos Linguísticos). Centro de Ciências Humanas e Naturais, Programa de Pós-Graduação em Linguística, Universidade Federal do Espírito Santo, Vitória, 2015. 
RASSI, Amanda Pontes; VALE, Oto Araújo. Tipologia das construções verbais em português do Brasil: uma proposta de classificação do verbo dar. v. 18, n. 2, Caligrama: Belo Horizonte, 2013. p. 105-30. 